\title{
RANCANG BANGUN APLIKASI PENDATAAN SENSUS EKONOMI BERBASIS MOBILE
}

\author{
CAHYO PRIANTO${ }^{1}$, NURUL LUTFIASIH ${ }^{2}$ \\ Teknik Informatika \\ Politeknik Pos Indonesia \\ Jl. Sariasih No.54, Sarijadi \\ cahyoprianto@poltekpos.ac.id, lutfiacn@gmail.com
}

\begin{abstract}
ABSTRAK
Badan Pusat Statistik (BPS) merupakan sebuah institusi pemerintah yang mempunyai hak untuk melakukan kegiatan statistik yaitu berupa sensus dan survei. BPS melakukan pengolahan data dari beberapa sensus, cotohnya yaitu tentang sosial dan kependudukan, ekonomi dan perdagangan, serta pertanian dan pertambangan. Setiap data dan keputusan yang diambil harus berdasarkan informasi yang valid dan akurat. Namun semakin meningkatnya permintaan data dan informasi maka akan berpengaruh pula pada meningkatnya kegiatan survei yang tidak sebanding dengan terbatasnya jumlah SDM. Meski BPS mempunyai sistem dan infrastruktur teknik informasi yang memadai, namun masih ada sistem yang belum sepenuhnya terintegrasi dengan baik. Sistem yang akan dibuat adalah sistem pada aplikasi yang digunakan BPS dalam pengolahan data sensus ekonomi untuk Usaha Mikro dan Kecil. Sistem tersebut dianalisis dengan cara pengumpulan data dengan menggunakan kuesioner. Sistem yang akan dianalisis tersebut diharapkan dapat dibuat aplikasi dengan menggunakan model Waterfall.Dengan menggunakan model Waterfall maka kualitas pengembangan yang dihasilkan akan lebih baik karena dilakukan secara bertahap sehingga sistem yang akan dikembangkan dapat membantu petugas dalam mengolah data.
\end{abstract}

Kata kunci: BPS, data, survei, informasi, Waterfall.

\begin{abstract}
Badan Pusat Statistik (BPS) is a government institution that has the right to conduct statistical activities such as census and survey. BPS conducts data processing from several censuses, namely social and population, economy and trade, and agriculture and mining. Any data and decisions taken should be based on the valid and accurate information. But the increasing demand for data and information will also affect the increase of survey activities that are not proportional to the limited number of human resources. Although BPS has adequate IT systems and infrastructure, there are still systems that are not fully integrated yet. The system to be created is a data entry system used by field officers for MSE data. The system is analyzed by collecting data by using a questionnaire. The system to be analyzed is expected to be made a mobile application using the Waterfall model.By using the Waterfall model then the quality of the resulting development will be better because it is done in stages so that the system will be developed to assist officers in processing the data.
\end{abstract}

Keywords: BPS, data, survey, information, Waterfall. 


\section{PENDAhUlUAN}

Badan Pusat Statistik (BPS) Provinsi Jawa Barat merupakan institusi pemerintahan yang bergerak di bidang pengolahan data statistik. BPS melakukan pengolahan data statistik dengan cara sensus dan survei. Sensus dan survei dilakukan agar data, informasi maupun keputusan yang diambil valid dan akurat. Sensus yang dilakukan oleh Badan Pusat Statistik Provinsi Jawa Barat yaitu seperti sensus tentang sosial dan kependudukan, ekonomi dan perdagangan, serta pertanian dan pertambangan. Kegiatan statistik tersebut akan menghasilkan data yang diperlukan oleh pemerintah, swasta maupun masyarakat lainnya.

Adanya banyak hal yang terjadi di suatu daerah kecil maupun daerah yang besar akan menyebabkan timbulnya permintaan ketersediaan berbagai jenis data dan informasi statistik untuk mendapatkan gambaran yang sebenarnya terjadi dan permasalahan yang dihadapi oleh setiap daerah. Semakin meningkatnya kebutuhan data dan informasi yang diperlukan oleh kementrian dan lembaga akan berpengaruh pula pada meningkatnya jumlah aktivitas survei yang diselenggarakan. Perningkatan aktivitas survei tersebut tidak sebanding dengan ketersediaan SDM profesional. Keterbatasan petugas ini juga yang menyebabkan tidak terpenuhinya kebutuhan akan data yang diperlukan. Ketepatan waktu dalam proses pengumpulan, pengolahan dan analisis hasil statistik juga sering terkendala akibat pelaksanaan proses survei dan kurangnya SDM.

Sesuai dengan latar belakang yang telah disebutkan maka akan dibangun aplikasi untuk membantu para petugas karena dalam pengambilan data yang dilakukan oleh petugas saat ini masih manual yaitu dengan cara mencatat data yang diperlukan. Namun cara ini juga terkadang tidak efektif karena data yang dicatat terkadang akan terjadi error jika dicatat secara digital nantinya. Maka dari itu untuk menghindari masalah seperti ini, dibuatlah aplikasi untuk membantu petugas dalam melakukan pendataan sehingga petugas tidak perlu manggunakan cara manual untuk mencatat. Hal ini bertujuan agar jika terjadi kesalahan dalam memasukan data maka petugas tidak perlu kembali ke tempat pendataan untuk menanyakan kembali data yang belum lengkap ataupun tidak lengkap.

\section{KERANGKA TEORI}

\subsection{Deskripsi Topik Yang Sama}

Pengetahuan dibagi dalam berbagai bagian salah satunya yaitu pengetahuan berbasis data. Pengetahuan tentang data ini dapat memanfaatkan penggunaan statistik karena dengan pendekatan statistik dapat memungkinkan untuk meringkas informasi yang terdapat dalam data [1]. Kejelasan dalam statistik juga sangat penting agar data yang dilaporkan tepat [2]. Data baru-baru ini dianggap sebagai aset berharga yang bisa membuat persaingan lebih atraktif [3]. Dalam ilmu data modern disebutkan bahwa data identik dengan fakta, dan demikian semakin banyak data yang dikumpulkan untuk analisis, semakin baik [4]. Pengumpulan data saat ini dapat melalui wawancara maupun kuesioner walaupun untuk sebagian orang cara ini kurang efisien [5]. Nantinya data yang diperoleh akan memunculkan kriteria-kriteria yang dapat digunakan untuk menentukan metode apa yang akan digunakan [6]. Maka dari itu hal penting yang harus diperhatikan adalah data yang dianalisis berdasarkan data yang tertulis [7]. Data tertulis tersebut kemudian dikumpulkan melalui aplikasi dan dilaporkan menjadi dokumen teknis [8]. Penggunaan aplikasi dalam pendataan dapat mengurangi jumlah waktu yang dibutuhkan untuk entry data. Hal ini dapat menjaga kualitas data dengan mencegah kesalahan ketik yang terjadi [9]. Namun data yang besar juga dapat menjadi batasan kemampuan perusahaan dalam hal menyimpan, memproses dan mengakses semua data yang dibutuhkan untuk fungsi yang efektif, dan untuk membuat keputusan [10]. Pesatnya pertumbuhan teknologi di berbagai bidang selama beberapa tahun terakhir telah 
meningkat [11]. Maka dari itu teknologi web juga meningkat pesat dalam pengembangan aplikasi yang responsif [12]. Hal ini memungkinkan bahwa produk perangkat lunak bisa terus berkembang dengan cepat dengan menambahkan fitur setiap harinya [13]. Dalam pengembangan aplikasi berbasis web juga menawarkan beberapa fitur yang fungsinya dapat membantu pekerjaan [14].

\subsection{Deskripsi Metode yang Sama}

Salah satu metode yang digunakan untuk pengembangan aplikasi yaitu waterfall yang mempunyai segmentasi hirarkis [15]. Dalam proyek pengembangan waterfall sejati, masingmasing mewakili tahap pengembangan perangkat lunak yang berbeda, dan setiap tahap umumnya selesai sebelum yang berikutnya dapat dimulai. Biasanya juga ada tahapan di antara misalnya, persyaratan harus ditinjau dan disetujui oleh pelanggan sebelum desain dapat dimulai [16].

\subsection{Sensus Ekonomi}

Sensus merupakan penghitungan jumlah penduduk, ekonomi, dan sebagainya yang dilakukan oleh pemerintah dalam jangka waktu tertentu dan dilakukan secara serentak dan bersifat menyeluruh. Pemerintah memiliki 3 kegiatan sensus utama yaitu sensus penduduk, sensus pertanian dan sensus ekonomi. Semua kegiatan sensus tersebut dilaksanakan oleh Badan Pusat Statistik (BPS).

Sesuai amanat Undang-Undang (UU) Nomor 16 Tahun 1997 tentang Statistik, Badan Pusat Statistik (BPS) berkewajiban melaksanakan kegiatan Sensus Ekonomi (SE) setiap sepuluh tahun sekali pada tahun yang berakhiran angka enam.

Sensus Ekonomi 2016 (SE2016) adalah kegiatan sensus ke empat, yang merupakan kegiatan pendataan lengkap atas seluruh unit usaha/perusahaan yang berada dalam batas-batas wilayah Negara Kesatuan Republik Indonesia (NKRI). Seluruh informasi yang dikumpulkan bermanfaat untuk mengetahui gambaran tentang performa dan struktur ekonomi baik menurut wilayah, lapangan usaha, maupun skala usaha.

Pelaksanaan SE2016 dilakukan dalam beberapa tahapan, mulai dari persiapan, listing/pendaftaran unit usaha/perusahaan, pencacahan lengkap unit usaha/perusahaan menengah dan besar (UMB), dan pencacahan sampel unit usaha/perusahaan mikro dan kecil (UMK), sampai dengan diseminasi hasil. Tujuan dari sensus ekonomi adalah mendapatkan jumlah usaha dan karakteristik usaha serta informasi lain terkait unit usaha.

Jika pelaksanaan sensus terhadap populasi sulit dilakukan, maka dilakukanlah kegiatan survei yang tujuan utamanya adalah untuk menduga karakteristik populasi. Survey merupakan kegiatan pengumpulan data dan informasi dengan cara mengamati sebagai elemen dari populasi. Sebagian elemen dari populasi tersebut disebut juga dengan sampel. Karena survey digunakan untuk menduga populasi, maka pengambilan sampel memerlukan teknik yang tepat agar sampel yang diambil benar-benar mewakili populasi [17].

\subsection{Real Time System}

Real-Time System atau sistem waktu nyata merupakan sistem yang tunduk pada suatu kendala yaitu batas waktu operasional dari sistem secara responsif. Real-Time System juga bisa disebut keadaan yang sedang berjalan, apa yang kita rasakan, dengarkan dan kita lihat pada saat itu. Contohnya yaitu pada saat kita menulis naskah dengan komputer, kita memasukkan tulisan menggunakan keyboard. Dalam toleransi waktu yang telah ditentukan, komputer akan menampilkan tulisan tersebut ke layar komputer. Toleransi waktu ini 
hitungannya sepersekian detik sehingga mata kita tidak dapat melihatnya. Jika data yang kita ketik muncul sekian detik kemudian maka kondisi ini dikatakan bukan waktu nyata.

\subsection{Job Scheduler}

Job Scheduler merupakan sebuah program yang memungkinkan perusahaan untuk membuat penjadwalan dan dalam beberapa kasus, perusahaan dapat memantau pekerjaan komputer. Job Scheduler dapat memulai dan mengelola pekerjaan secara otomatis dengan memproses pernyataan bahasa pemrograman yang telah disisipkan saat proses pembuatan aplikasi [18].

\section{METODE}

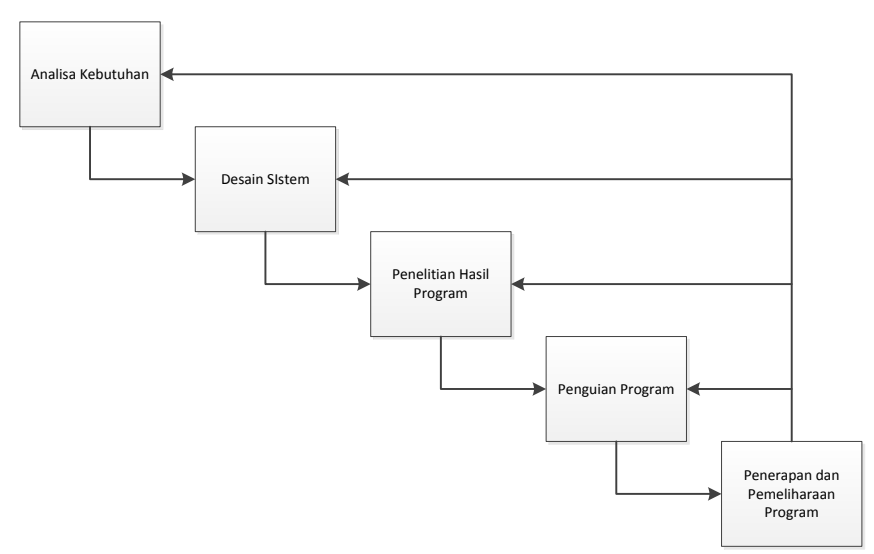

Gambar 3.1 Metodologi Penelitian

Berikut adalah penjelasan dari tahap-tahap yang dilakukan di dalam model ini menurut Pressman:

1. System/ Information Engineering and Modeling. Awal dari sistem ini yaitu diawali dengan mencari kebutuhan sistem yang akan diaplikasikan ke dalam bentuk software. Hal ini sangat penting, mengingat software harus dapat berinteraksi dengan elemen-elemen yang lain seperti hardware, database, dsb. Pada proses ini mengamati apa saja kebutuhan sistem yang diinginkan perusahaan tersebut. Dari pengamatan tersebut kemudian diketahui permasalahan yang dihadapi kemudian dianalisa dan dirumuskan solusi yang memungkinkan untuk dikembangkan.

Tabel 3.1 Kuesioner

\begin{tabular}{|c|c|c|c|c|c|c|}
\hline \multirow{2}{*}{\multicolumn{2}{|c|}{$\begin{array}{l}\text { KEGUNAAN } \\
\text { Sistem Teknologi Informasi }\end{array}$}} & SS & $\mathbf{S}$ & $\mathbf{R}$ & TS & STS \\
\hline & m Teknologi Informasi & & & & & \\
\hline 1 & Aplikasi UMK Data ini dapat dengan mudah dioperasikan & & & & & \\
\hline 2 & $\begin{array}{l}\text { Dalam menggunakan aplikasi ini, saya dapat dengan } \\
\text { mudah melakukan input data }\end{array}$ & & & & & \\
\hline 3. & $\begin{array}{l}\text { Secara keseluruhan, penggunaan aplikasi ini } \\
\text { memuaskan }\end{array}$ & & & & & \\
\hline \multicolumn{7}{|c|}{ Proses Input Aplikasi Pengolahan Data } \\
\hline 4. & $\begin{array}{l}\text { Saya dapat beradaptasi dengan aplikasi ini dengan } \\
\text { mudah }\end{array}$ & & & & & \\
\hline \multirow[b]{2}{*}{6.} & Aplikasi UMK Data mudah dipahami aturannya & & & & & \\
\hline & $\begin{array}{l}\text { Banyaknya aturan sistem dari aplikasi tidak membuat } \\
\text { saya bingung dalam menggunakannya }\end{array}$ & & & & & \\
\hline \multicolumn{7}{|c|}{ Pengembangan Aplikasi } \\
\hline 7. & $\begin{array}{l}\text { Aplikasi tidak perlu dikembangkan karena cara } \\
\text { penggunaannya sederhana dan mudah dipahami }\end{array}$ & & & & & \\
\hline
\end{tabular}




\begin{tabular}{|l|l|l|l|l|l|l|}
\hline 8. & $\begin{array}{l}\text { Fitur pada aplikasi sudah cukup untuk membantu para } \\
\text { petugas lapangan. }\end{array}$ & & & & & \\
\hline 9. & Tampilan aplikasi ini mudah dikenali & & & & & \\
\hline
\end{tabular}

\section{Uji Validitas}

$$
r_{x y}=\frac{N \Sigma x y_{-(\Sigma x)}\left(\sum y\right)}{\sqrt{\left(N \Sigma x^{2}-\left(\sum x\right)^{2}\left(N \Sigma y^{2}-(\Sigma y)^{2}\right)\right.}}
$$

\section{Rumus 3.1 Rumus Kolerasi Product Moment}

Pada kuesioner ini terdapat 10 responden dimana pada $r$ tabel nilai dari 10 adalah 0.6319 . Pada uji validitas ini $r$ hitung harus lebih besar dari $r$ tabel $(r$ hitung $>r$ tabel). $z$

\section{Uji Reliabilitas}

$$
r_{11}=\left(\frac{n}{n-1}\right)\left(1-\frac{\sum \sigma_{t}^{2}}{\sigma_{t}^{2}}\right)
$$

\section{Rumus 3.2 Rumus Alpha Cronbach}

Keterangan :

$$
\begin{array}{ll}
\mathrm{r}_{11} & =\text { reliabilitas instrumen } \\
\mathrm{k} & =\text { banyaknya butir pertanyaan } \\
\Sigma \sigma b^{2} & =\text { jumlah varians butir tiap pertanyaan } \\
\Sigma \sigma 1^{2} & =\text { varians total }
\end{array}
$$

Apabila dilakukan uji keandalan atau reliabilitas maka di dapat hasil sebagai berikut:

\section{Tabel 3.2 Hasil Uji Reliabilitas Variabel Keseluruhan}

Reliability Statistics

\begin{tabular}{|r|r|}
\hline $\begin{array}{c}\text { Cronbach's } \\
\text { Alpha }\end{array}$ & N of Items \\
\hline .893 & 9 \\
\hline
\end{tabular}

Berdasarkan tabel uji reliabilitas di atas dapat disimpulkan bahwa sub variabel keseluruhan pada sistem adalah reliabel atau andal, karena cronbach's alpha yang di dapat adalah 0.893 dan lebih besar dari minimal koefisien 0,6319. Dengan demikian uji reliabilitas dapat disimpulkan andal.

\section{Hasil Uji Distribusi Frekuensi}

Distribusi Frekuensi digunakan untuk meberikan gambaran sekilas dan ringkas dari sekelompok data dalam satu variabel. Data tersebut kita masukan jadi satu tabel frekuensi. 


\section{Analisis Sistem Yang Sedang Berjalan}

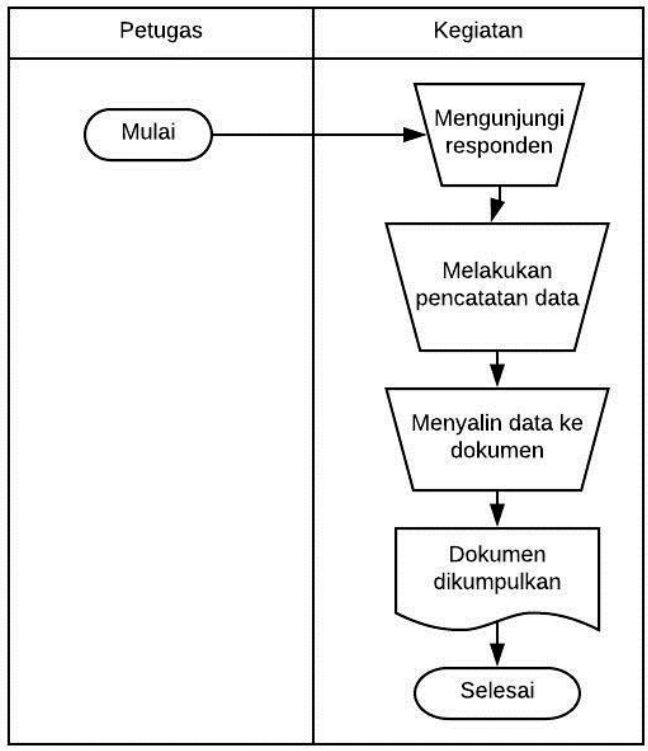

Keterangan:

Gambar 3.2 Sistem yang Sedang Berjalan

Proses yang sedang berjalan pada kegiatan yang dilakukan petugas lapangan yaitu petugas mengunjungi responden untuk melakukan pancatatan data secara manual. Kemudian data yang telah dicatat tersebut disalin kedalam dokumen yang telah disediakan pihak BPS. Setelah data disalin, maka dokumen tersebut dikumpulkan kembali ke BPS untuk diproses lebih lanjut.

\section{Analisis Sistem Yang Akan Dibangun}

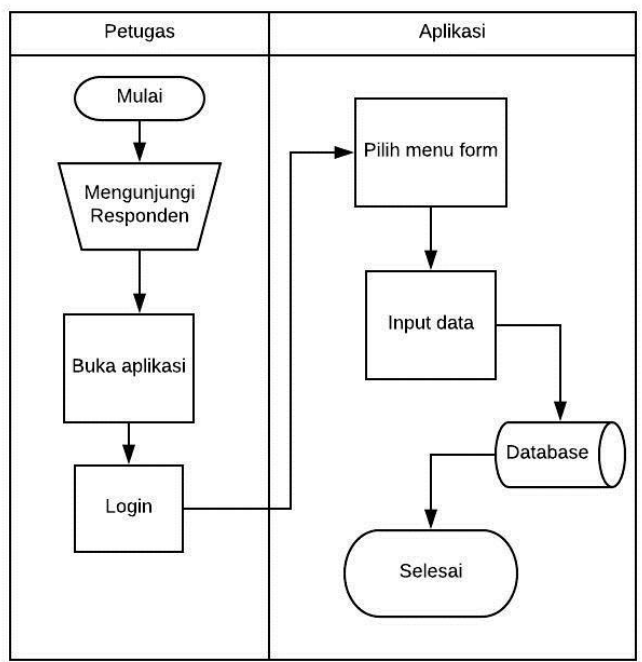

\section{Gambar 3.3 Sistem yang Akan Dibangun}

Keterangan:

Pada sistem yang akan dibangun, petugas lapangan mengunjungi responden. Kemudian petugas melakukan pendataan dengan membuka aplikasi, login terlebih dahulu kemudian pilih menu form. Data yang diinputkan pada menu form tersebut akan disimpan ke database langsung. 
2. Software Requirements Analysis. Sistem ini diwali dengan pencarian kebutuhan yang difokuskan untuk mengetahui karakter dari program/aplikasi yang akan dibuat, maka para programmer harus mengerti tentang informasi yang dibutuhkan dari software, misalnya fungsi yang dibutuhkan, user interface, dsb. Tahap pertama dan kedua model Pressman ini memiliki proses yang sama seperti model yang dikemukakan Pascapraharastyan, dkk.

3. Design (Implementation And Unit Testing). Proses ini digunakan untuk mengubah kebutuhan-kebutuhan diatas menjadi representasi ke dalam bentuk gambaran rencana secara jelas software sebelum coding. Desain harus dapat mengimplementasikan kebutuhan yang telah disebutkan pada tahap sebelumnya. Coleyconsulting menyatakan desain perangkat lunak mencakup desain sistem dan desain komponen.

4. Coding (Implementation And Unit Testing). Setelah dilakukan penggambaran rencana pembuatan software, maka desain tadi harus diubah bentuknya menjadi bentuk yang dapat dimengerti oleh mesin, yaitu ke dalam bahasa pemrograman. Tahap ini merupakan implementasi yang nantinya dikerjakan oleh programmer. Pada bagian ini, penulis menggunakan Job Scheduler. Job Scheduler dapat memulai dan mengelola pekerjaan secara otomatis dengan memproses pernyataan bahasa pemrograman yang telah disisipkan saat proses pembuatan aplikasi

5. Testing (Integration And Sytem Testing). Uji coba terhadap program yang dibuat, apabila error maka harus kembali ke tahapan coding untuk mencari kesalahan yang ada. Dalam aplikasi ini menggunakan Job Schedling. Job Scheduler merupakan sebuah program yang memungkinkan perusahaan untuk membuat penjadwalan dan dalam beberapa kasus, perusahaan dapat memantau pekerjaan komputer.

Tahapan akhir dimana sistem yang baru diuji kemampuan dan keefektifannya sehingga didapatkan kekurangan dan kelemahan sistem yang kemudian dilakukan pengkajian ulang dan perbaikan terhadap aplikasi menjadi lebih baik dan sempurna. Dalam pengujian ini, penulis akan menggunakan pengujian blackbox. Pengujian blackbox merupakan pengujian yang berfokus pada persyaratan fungsional perangkat lunak dan kuesioner untuk menguji hasil pengembangan pada aplikasi entry data yang dilakukan penulis.

\section{Pengujian Alpha}

Tabel 3.3 Rencana Pengujian Alpha

\begin{tabular}{|l|l|l|l|}
\hline & Item Pengujian & \multicolumn{1}{|c|}{ Detail Pengujian } & Jenis Pengujian \\
\hline 1 & Daftar & Daftar Pengguna & Blackbox \\
\hline 2 & Login & Login pengguna & Blackbox \\
\hline 3 & Tambah Data & Tambah, Updatedata UMK & Blackbox \\
\hline 4 & Kirim Pesan & Kirim pesan & Blackbox \\
\hline
\end{tabular}




\section{Pengujian Kuesioner}

Tabel 3.4 Pengujian Kuesioner

\begin{tabular}{|c|l|c|c|}
\hline \multirow{2}{*}{ No } & \multicolumn{1}{|c|}{ Pertanyaan } & \multicolumn{1}{c|}{ Alternatif Jawaban } \\
\cline { 4 - 4 } & \multicolumn{1}{|c|}{$\begin{array}{c}\text { Setuju } \\
\text { Uroses bisnis pada pengembangan aplikasi } \\
\text { UMK Data tersebut mudah dipahami }\end{array}$} & & \\
\hline 2 & $\begin{array}{l}\text { Desain pengembangan aplikasi UMK Data } \\
\text { tersebut dapat membuat proses pekerjaan } \\
\text { lebih cepat dilakukan }\end{array}$ & & \\
\hline 3 & $\begin{array}{l}\text { Fitur input data secara offline pada aplikasi } \\
\text { UMK Data dapat membantu pekerjaan }\end{array}$ & & \\
\hline 4 & $\begin{array}{l}\text { Aplikasi dirasa sudah membantu pekerjaan } \\
\text { petugas lapangan }\end{array}$ & & \\
\hline 5 & $\begin{array}{l}\text { Saya merasa puas dengan aplikasi UMK data } \\
\text { tersebut }\end{array}$ & & \\
\hline
\end{tabular}

Skala pengukuran variabel dalam penelitian ini menggunakan skala Guttman. Skala ini membutuhkan jawaban jelas yaitu tegas dan konsisten. seperti setuju atau tidak setuju. Hasil perhitungan jawaban responden sebagai berikut :

1. Pernyataan Pertama : Proses bisnis pada pengembangan aplikasi UMK Data tersebut mudah dipahami.

1. Respoden yang menjawab setuju $=10$

Total Skor / N X $100 \%$

$=10 / 10 \times 100 \%=100 \%$

2. Responden yang menjawab tidak setuju $=0$

Total Skor / N X $100 \%$

$=0 / 10 \times 100 \%=0 \%$

2. Pernyataan Kedua : Desain pengembangan aplikasi UMK Data tersebut dapat membuat proses pekerjaan lebih cepat dilakukan

1. Respoden yang menjawab setuju $=10$

Total Skor / N X $100 \%$

$=10 / 10 \times 100 \%=100 \%$

2. Responden yang menjawab tidak setuju $=0$

Total Skor / N X $100 \%$

$=0 / 10 \times 100 \%=0 \%$

3. Pernyatan Kedua : Fitur input data secara offline pada aplikasi UMK Data dapat membantu pekerjaan

1. Respoden yang menjawab setuju $=10$

Total Skor / N X $100 \%$

$=10 / 10 \times 100 \%=100 \%$

2. Responden yang menjawab tidak setuju $=0$

Total Skor / N X $100 \%$

$=0 / 10 \times 100 \%=0 \%$

4. Pernyataan keempat : Aplikasi dirasa sudah membantu pekerjaan petugas lapangan

1. Responden yang menjawab setuju $=8$

Total Skor / N X $100 \%$

$=8 / 10 \times 100 \%=80 \%$

2. Responden yang menjawab tidak setuju $=2$

Total Skor / N X $100 \%$

$=2 / 10 \times 100 \%=20 \%$

5. Pernyataan kelima : Saya merasa puas dengan aplikasi UMK data tersebut

1. Responden yang menjawab setuju $=9$ 
Total Skor / N X $100 \%$

$=9 / 10 \times 100 \%=90 \%$

2. Responden yang menjawab tidak setuju $=1$

Total Skor / N X $100 \%$

$=1 / 10 \times 100 \%=10 \%$

Kesimpulan hasil pengujian:

1. Dari hasil pengujian dapat disimpulkan bahwa aplikasi yang dikembangkan penulis mudah dipahami oleh responden.

2. Dari hasil pengujian dapat disimpulkan bahwa desain aplikasi UMK Data tersebut dapat membuat pekejaan lebih cepat dilakukan.

3. Dari hasil pengujian diatas dapat disimpulkan bahwa fitur input data secara offline dapat membantu pekerjaan responden.

4. Dari hasil pengujian dapat disimpulkan bahwa responden merasa aplikasi yang dikembangkan penulis sudah dapat membantu petugas untuk melakukan pendataan dengan lebih maksimal.

6. Maintenance (Operation And Maintenance). Pemeliharaan, pada tahapan ini perubahan dan upgrading dilakukan berdasarkan 2 kondisi yaitu permintaan user dan suporting (dukungan) dengan software lain.

\section{HASIL}

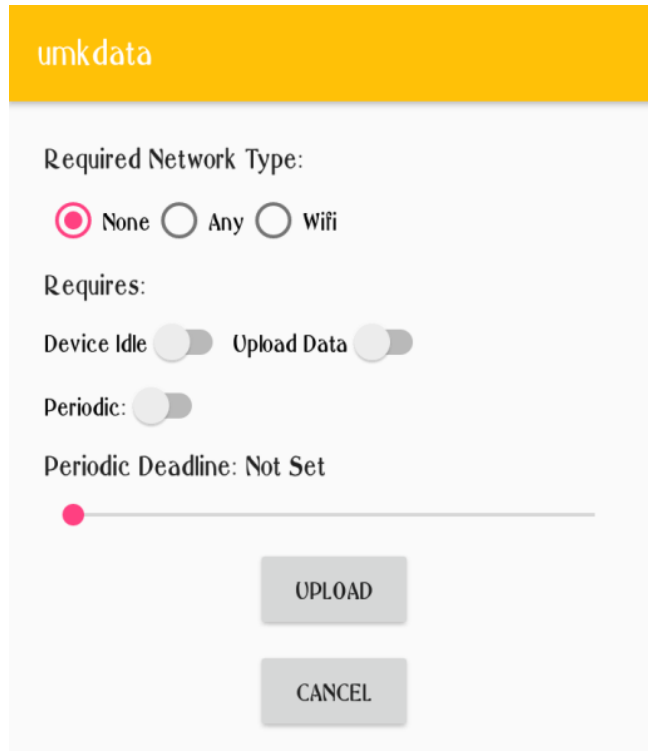

Gambar 4.1 Hasil

Keterangan:

Jika user menginputkan data secara offline, maka data bisa diatur kapan harus di upload. Pilihan Any dipakai untuk jaringan internet apapun. Jika pilihan Wifi maka data akan di upload ke firebase jika aplikasi tersambung ke jaringan wifi yang ada. Pada bagian Requires, terdapat 2 pilihan yaitu Device Idle yaitu untuk upload data tanpa notifikasi dan pilihan Upload Data untuk upload data dengan notifikasi. Jika user menggunakan pilihan Periodic. Pada bagian Periodic Deadline, user dapat mengatur berapa jam sekali data harus di upload ke firebase. 


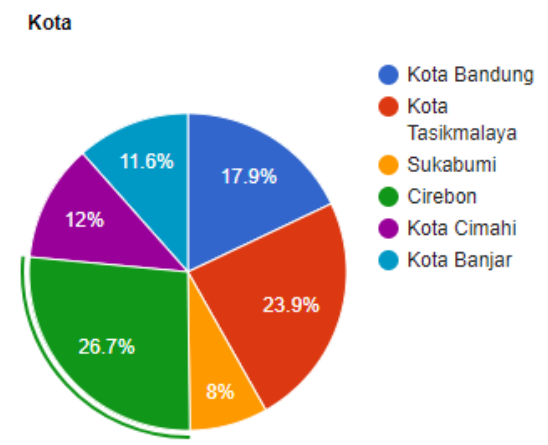

Keterangan:

\section{Gambar 4.2 Data Grafik}

Pada pihak admin, Data dapat dimunculkan dalam bentuk grafik. Grafik tersebut tentang presentase penduduk yang mempunyai usaha pada kota/kabupaten di Jawa Barat.

\section{KESIMPULAN}

Eksperimen yang dilakukan berdasarkan kuesioner yang disebar kepada 10 mitra BPS yang terdiri dari beberapa pernyataan mengenai aplikasi perlu dibuat atau tidak. Setelah kuesioner dikumpulkan dan dihitung, hasil yang didapatkan yaitu valid, aplikasi bisa dikembangkan. Setelah pengembangan aplikasi selesai, penulis mengajukan kembali kuesioner mengenai aplikasi yang telah dikembangkan dan mengajukan beberapa pernyataan tentang aplikasi tersebut dan hasil dari perhitungan kuesioner yang diajukan ini maka hasilnya responden merasa terbantu dengan aplikasi tersebut.

\section{UCAPAN TERIMA KASIH}

Penulis mengucapkan terima kasih kepada pihak-pihak yang telah membantu serta memberikan dukungan dan bantuan baik secara moril ataupun material.

\section{DAFTAR RUJUKAN}

[1] M. Pota, M. Esposito, and G. D. Pietro, "Likelihood-fuzzy analysis: From data, through statistics, to interpretable fuzzy classifiers," International Journal of Approximate Reasoning, vol. 93, pp. 88 - 102, 2018.2 [Online]. Available: http://www.sciencedirect.com/science/article/pii/S0888613X1730659X

[2] M. Stecker, P. Pasqualetti, R. J. Barry, Z. J. Daskalakis, H. R. Siebner, and U. Ziemann, "Statistical data analyses for clinical neurophysiology," Clinical Neurophysiology, vol. 128, no. 10, pp. 1837 1838, 2017. [Online]. Available: http://www.sciencedirect.com/science/article/pii/S1388245717308830

[3] A.-A. Khalil, A. Reza, P. A. Junaedi, and B. Kanigoro, "Data visualization application for analyzing public company financial statement," Procedia Computer Science, vol. 59, pp. 45 - 53, 2015, international Conference on Computer Science and Computational Intelligence (ICCSCI 2015). [Online]. Available: http://www.sciencedirect.com/science/article/pii/S1877050915018657

[4] S. Scheider, F. O. Ostermann, and B. Adams, "Why good data analysts need to be critical synthesists. determining the role of semantics in data analysis," Future Generation Computer Systems, vol. 72, pp. $11 \quad-\quad 22, \quad 2017 . \quad$ [Online]. Available:http://www.sciencedirect.com/science/article/pii/S0167739X17303047

[5] X. Ren, Y. Zhao, W. Zeiler, G. Boxem, and T. Li, "A data mining approach to analyze occupant behavior motivation," Procedia Engineering, vol. 205, pp. 2442- 2448, 2017, 10th International Symposium on Heating, Ventilation and Air Conditioning, ISHVAC2017, 19-22 October 2017, Jinan, China. [Online]. Available: http://www.sciencedirect.com/science/article/pii/S1877705817345307 
[6] G. Tan, D. A. Mortona, and I. Larson, "Strategies to analyse data obtained from liquid intrusion experiments of loose porous materials," Journal of Pharmaceutical and Biomedical Analysis, vol. 145, pp. $711 \quad-\quad 717,2017 . \quad$ [Online]. Available : http://www.sciencedirect.com/science/article/pii/S0731708517304892

[7] L. Birglen and T. Schlicht, "A statistical review of industrial robotic grippers, "Robotics and Computer-Integrated Manufacturing, vol. 49, pp. 88 - 97, 2018. [Online]. Available: http://www.sciencedirect.com/science/article/pii/S0736584516304240

[8] Y. Qiu, M. Wei, B. Bai, and C. Mao, "Data analysis and application guidelines for the microgel field applications," Fuel, vol. 210, pp. 557 - 568, 2017. [Online]. Available:http://www.sciencedirect.com/science/article/pii/S001623611731089X

[9] S. L. Rossato, T. T. Fung, and M. P. Rodrigues, "A data entry system for dietary surveys based on visual basic for applications programming," Journal of the Academy of Nutrition and Dietetics, vol. 117, no. 8, pp. $1165-1170,2017$. [Online]. Available: http://www.sciencedirect.com/science/article/pii/S2212267216309509

[10] M. Birjali, A. Beni-Hssane, and M. Erritali, "Analyzing social media through big data using infosphere biginsights and apache flume," Procedia Computer Science, vol. 113, pp. $280-285$, 2017, the 8th International Conference on Emerging Ubiquitous Systems and Pervasive Networks (EUSPN 2017) / The 7th International Conference on Current and Future Trends of Information and Communication Technologies in Healthcare (ICTH-2017) / Affiliated Workshops. [Online]. Available: http://www.sciencedirect.com/science/article/pii/S1877050917317088

[11]S. Golodetz, C. Nicholls, I. Voiculescu, and S. Cameron, "Two tree-based methods for the waterfall," Pattern Recognition, vol. 47, no. 10, pp. 3276 - 3292, 2014. [Online]. Available: http://www.sciencedirect.com/science/article/pii/S0031320314001630

[12]B. Berman, "Planning and implementing effective mobile marketing programs," Business Horizons, vol. 59, no. 4, pp. 431 - 439, 2016. [Online]. Available: http://www.sciencedirect.com/science/article/pii/S0007681316300076

[13]S. Apichatibutarapong, "Business forecasting technique on mobile devices by using $r$ programming," Procedia - Social and Behavioral Sciences, vol. 197, pp. 1377 - 1382, 2015, 7th World Conference on Educational Sciences. [Online]. Available: http://www.sciencedirect.com/science/article/pii/S1877042815040756

[14]E. G. Boix, C. Scholliers, W. D. Meuter, and T. DâAZHondt, "Programming mobile contextaware applications with totam," Journal of Systems and Software, vol. 92, pp. 3 - 19, 2014. [Online]. Available: http://www.sciencedirect.com/science/article/pii/S0164121213001799

[15] L. Briz-Ponce, A. Pereira, L. Carvalho, J. A. Juanes-MÃlndez, and F. J. GarcÃ-a- PeÃsalvo, "Learning with mobile technologies students behavior," Computers in Human Behavior, vol. 72, pp. $612-$ 620, $2017 . \quad$ [Online]. Available: http://www.sciencedirect.com/science/article/pii/S0747563216303545

[16] H. E. Kim, Y.-J. Hong, M.-K. Kim, Y. H. Jung, S. Kyeong, and J.-J. Kim, "Effectiveness of self-training using the mobile-based virtual reality program in patients with social anxiety disorder," Computers in Human Behavior, vol. 73, pp. $614-619$, 2017. [Online]. Available: http://www.sciencedirect.com/science/article/pii/S0747563217302595

[17]Bpshq.2016. "Sensus Ekonomi 2016" . Jakarta . [Online]. Available : https://se2016.bps.go.id/Lanjutan/index.php/metadata/

[18] Hanafiah, H. (2014). Penggunaan Fair Scheduler dan FIFO pada Job Scheduling dengan Karakteristik Job pada Hadoop. Bandung. 